4 Myllykangas-Luosujärvi $\mathrm{R}$, Aho $\mathrm{K}$, Isomäki $\mathrm{H}$. Mortality in rheumatoid arthritis. Semin Arthritis Rheum 1995; 25: 193-202.

5 Vinyard P G, Tatzber F, Esterbauer H, Kus M L Blake D R, Morris C J. Presence of foam cel containing oxidised low density lipoprotein in the synovial membrane from patients with rheumatoid arthritis. Ann Rheum Dis 1993, 52: 677-80.

6 Vaarala O, Alfthan G, Jauhiainen M, LeirisaloRepo M, Aho K, Palosuo T. Crossreaction between antibodies to oxidised low-density lipoprotein and to cardiolipin in systemic lupus erythematosus. Lancet 1993; 341: lupus

7 Vaarala O, Puurunen M, Lukka $M$, et al. Affinity-purified cardiolipin-binding antibodies show heterogeneity in their binding to oxidised low-density lipoprotein. Clin Exp Immunol. In press.

8 Larsen A, Dale K, Eek M. Radiographic evaluation of rheumatoid arthritis and related conditions by standard reference films. Acta Radiol Diagn 1977; 18: 481-91.

9 Vaarala $O$. Binding profiles of cardiolipinbinding antibodies in SLE and infectious diseases. ₹ Autoimmun 1991; 4: 819-30.

\section{Age of onset in successive generations of patients with a spondyloarthropathy}

Juvenile spondyloarthropathy (JSPA) is as yet not a fully defined disorder, ${ }^{1}$ but can be considered as the juvenile form of the adult spondyloarthropathy (SPA). Preliminary criteria for the latter have been proposed, ${ }^{2}$ the tip of the iceberg being ankylosing spondylitis. These criteria are also applicable for JSPA. ${ }^{3}$ The clinical presentation of JSPA may differ from adult onset SPA, ${ }^{4}$ but eventually a considerable percentage of patients with JSPA will develop a clinical picture indistinguishable from adult SPA.

Ankylosing spondylitis has a strong association with the presence of the HLA-B27 antigen. ${ }^{5}$ The risk for a first degree HLA-B27 positive relative of a patient with ankylosing spondylitis developing that disease is about $20 \%{ }^{6}$ The higher prevalence of SPA in parents of children with early onset pauciarticular juvenile chronic arthritis than in the general population was reported previously. Possibly, the prevalence of SPA among parents with a child with JSPA might also be higher than in the general population. We report that there is a tendency towards an earlier onset of SPA in the next generation.

Seven index patients were seen in the paediatric rheumatology clinic and presented with JSPA according to the European Spondyloarthropathy Study Group (ESSG) criteria, ${ }^{2}$ around the age of 10 (table). The age of onset in the children varied from 5 to 10 years (mean 8.3 ) and in the parents from 21 to 42 years (mean $31 \cdot 1$ ). The year of onset is the year the first complaints relating to the SPA were noticed. The clinical picture of the

juvenile patients consisted of an asymmetric, IgM rheumatoid factor negative oligoarthritis with a predilection for joints in the lower extremeties combined with features of enthesitis. Symptoms of inflammation of the lower lumbar spine were rare at presentation. All the children carried the HLA-B27 antigen. One of the parents of these seven index patients developed SPA (retrospectively diagnosed) according to the ESSG criteria ${ }^{2}$ in their third or fourth decade.

There may be several explanations for our observation. It could be a coincidenta finding or biased by our daily practice: a parent might pay more attention to joint or back complaints when his/her child is diagnosed as having JSPA. It might also be explained by a simultaneous infection in the presence of the HLA-B27 antigen in the family members of two generations. A marked discrepancy between the calendar years of onset for the children and parents pleads against temporal clustering. Another explanation might be genetic anticipation, which has been clearly delineated in some diseases, where there is a tendency for the disease to start with an earlier age of onset over subsequent generations. This phenomenon has been described in several monogenic neurodegenerative disorders and possibly exists in familial rheumatoid arthritis. ${ }^{8}$ Recent observations suggest that factors other than genetic factors may be associated with SPA. ${ }^{9}$ A variation in age of onset (8-51 years) was noted in one multicase family with a tendency towards an earlier age of onset in successive generations. ${ }^{10}$

Extended studies of HLA and non-HLA genes are required to answer the question whether the phenomenon of genetic anticipation occurs in SPA.

As unstable trinucleotide repeats have been described in neurodegenerative diseases correlating with the clinical phenomenon of genetic anticipation it may be worth looking for unstable genetic elements in familial SPA.

The authors are greatly indebted to $\operatorname{Dr} C M$ Deighton for his critical reading of the manuscript.

R HERTZBERGER-TEN CATE Department of Pediatrics, University Hospital Leiden The Netherlands

B A C DIJKMANS Department of Rheumatology Free University Hospital Amsterdam, The Netherlands

Correspondence to: Professor Dr B A C Dijkmans, Free University Hospital Amsterdam, Departmen of Rheumatology, Room B418, PO Box 7057, 1007 MB Amsterdam, The Netherlands.

1 Prieur A M, Listrat V, Dougados M, Amor B. Critéres de classification des spondyloarthropathies chez les enfants. Arch Fr Pediatr 1993; 50: 379-85.

2 Dougados $M$, van der Linden S, Juhlin R, et al The European Spondyloarthropathy Study

Age of onset and year of onset of index patient and parent with a spondyloarthropathy

\begin{tabular}{lcllll}
\hline Child & $\begin{array}{l}\text { Age of } \\
\text { onset (years) }\end{array}$ & $\begin{array}{l}\text { Year of } \\
\text { onset }\end{array}$ & Parent & $\begin{array}{l}\text { Age of } \\
\text { onset (years) }\end{array}$ & $\begin{array}{l}\text { Yeaqr of } \\
\text { onset }\end{array}$ \\
\hline$M^{\star}$ & 9 & 1988 & M & 21 & 1967 \\
$F^{\star}$ & 5 & 1981 & M & 35 & 1985 \\
M & 9 & 1988 & F & 30 & 1980 \\
M & 8 & 1983 & F & 25 & 1993 \\
M & 9 & 1990 & F & 31 & 1979 \\
M & 10 & 1990 & M & 25 & 1983 \\
\hline
\end{tabular}

${ }^{\star} M=$ male $;=$ female.
Group preliminary criteria for the classification of spondyloarthropathy. Arthritis Rheum 1991; 34: 1218-27.

3 Prieur A M, Dougados M, Listrat V, Amor B Evaluation of four sets of criteria for spondyloarthropathy in children. Arthritis Rheum 1992; 35: S190.

4 Azouz E M, Duffy C M. Juvenile spondyloarthropathies: clinical manifestations and medical imaging. Skeletal Radiol 1995; 24: 399-408.

5 Maclean I L, Igball S, Woo P, et al. HLA-B27 subtypes in the spondyloarthropathies. Clin Subtypes in the spondyloarth

6 Linden S J van der, Valkenburg H A de Jongh B M, Cats A. The risk of developing ankylosing spondylitis in HLA-B27 positive individuals. Arthritis Rheum 1984; 27 : 241-9.

7 Hertzberger-ten Cate R, Dijkmans B A C Increased prevalence of spondyloarthropathies in parents of children with pauciarticular juvenile chronic arthritis, type 1. Clin Rheumatol 1993; 12: 361-3:

8 Deighton C M, Thomson G. Genetic anticipation and musculoskeletal disease. Ann pation and musculoskele

9 Calin A, Kennedy G, Edmunds L, Will R Familial versus sporadic ankylosing Familial versus sporadic ankylosing
spondylitis. Arthritis Rheum 1993; 36: spondylitis.

10 Kidd $B$ L, Wilson $P$ J, Evans $P \quad R$ Cawley M I D. Familial aggregation of undifferentiated spondyloarthropathy associated with HLA-B27. Ann Rheum Dis 1995; 54 125-7.

\section{Quinine induced lupus- like syndrome and cardiolipin antibodies}

A large number of drugs are known to cause a clinical syndrome resembling systemic lupus erythematosus. ${ }^{1}$ The antiarrhythmic agent quinidine has occasionally been reported to cause such a syndrome..$^{2-4}$ Additionally, the presence of cardiolipin antibodies has been described in patients receiving phenothiazine,${ }^{5}$ procainamide, ${ }^{6}$ and ethosuximide ${ }^{7}$ treatment.

Quinine is an antimalarial drug analogue to quinidine that can also produce several autoimmune abnormalities, ${ }^{89}$ but a lupuslike syndrome and production of cardiolipin antibodies induced by this drug have not been previously described. We report a case of well documented quinine induced lupuslike syndrome in which cardiolipin antibodies were also found.

A 30 year old white woman was admitted to our hospital in May 1994 because of fever chills, and diaphoresis of three days' duration. Six weeks before admission the patient had been on vacation in Cameroon, but she did not take any prophylaxis for malaria. Physical examination was unremarkable at time of admission except for fever up to $40^{\circ} \mathrm{C}$. Laboratory examinations disclosed a packed cell volume of 0.37 , haemoglobin $117 \mathrm{~g} / \mathrm{l}$, white blood cell count $3.8 \times 10^{9} / 1$ (76\% neutrophils, $20 \%$ lymphocytes, $4 \%$ monocytes), and platelet count of $150 \times 10^{9}$. Thick smears showed Plasmodium falciparum parasitaemia of $1 \%$. Direct examination of stool and stool cultures were negative for other parasites. Blood cultures were also negative. Antinuclear, antitissue, and phospholipid antibodies were not detected. The patient was diagnosed as having malaria and treated with quinine sulphate $600 \mathrm{mg}$ three times daily.

Forty eight hours into treatment the patient was afebrile and a thick smear became negative for malaria. After six days of treatment the patient complained of dyspnoea and constant retrosternal chest 